\title{
Tissue microarray construction for salivary gland tumors study
}

\author{
Felipe Paiva-Fonseca ${ }^{1}$, Oslei-Paes de-Almeida ${ }^{2}$, Ana-Lúcia-Carrinho Ayroza-Rangel ${ }^{3}$, Pablo Agustin-Vargas ${ }^{2}$
}

${ }^{1}$ DDS. Department of Oral Diagnosis, Oral Pathology Section, Piracicaba Dental School, State University of Campinas - São Paulo - Brazil

${ }^{2}$ DDS, PhD. Department of Oral Diagnosis, Oral Pathology Section, Piracicaba Dental School, State University of Campinas São Paulo -Brazil

${ }^{3}$ DDS, PhD. Department of Pathology, State University of Western Paraná - Paraná - Brazil

Correspondence:

Piracicaba Dental School-State University of Campinas Unicamp

Department of Oral Diagnosis Oral Pathology Section

Av. Limeira, 901 ZipCode: 13414903

Piracicaba-São Paulo State-Brazil

pavargas@fop.unicamp.br

Paiva-Fonseca F, de-Almeida OP, Ayroza-Rangel ALC, Agustin-Vargas P. Tissue microarray construction for salivary gland tumors study. Med Oral Patol Oral Cir Bucal. 2013 Jan 1;18 (1):e1-6.

http://www.medicinaoral.com/medoralfree $01 / \mathrm{v} 1811 /$ medoralv18ilp1.pdf

Received: $12 / 01 / 2012$ Accepted: 07/06/2012

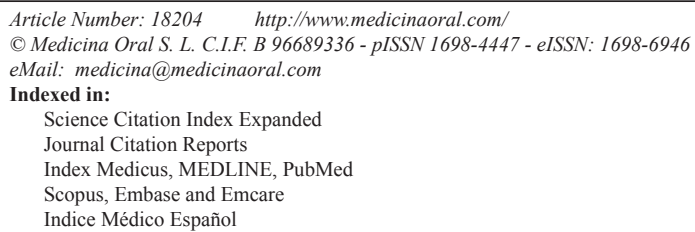

\begin{abstract}
Objective: To describe and discuss the design, building and usefulness of tissue microarray (TMA) blocks for the study of salivary gland tumors (SGTs).

Study Design: Two hundred thirty-eight formalin-fixed, paraffin-embedded SGTs were arranged in blocks of TMA using a manual tissue arrayer. Three representative cores of $1.0,2.0$ or $3.0 \mathrm{~mm}$ were taken from each original block and their characteristics were analyzed and described.

Results: It was created 12 TMA blocks that presented highly representative neoplastic cylinders. However, those neoplasias rich in cystic spaces such as mucoepidermoid carcinoma and Warthin tumor presented more difficulties to be sampled, as the neoplastic tissue available was scarce. Tissue damage and loss during TMA construction was estimated as $3.7 \%$.

Conclusion: Representative areas of SGTs, with relatively small loss of tissue, can be obtained with the construction of TMA blocks for molecular studies. However, tumors rich in cystic spaces present more difficulties to be adequately sampled.
\end{abstract}

Key words: Tissue microarray, tma, salivary gland tumors, immunohistochemistry.

\section{Introduction}

Salivary gland tumors (SGT) are uncommon neoplasms that account for $6 \%$ of all head and neck neoplasias and $0.3 \%$ of all cancers. The incidence of SGT per 100.000 persons is reportedly as 0.9 in women and 1.5 in men, with varied biological behavior and clinical outcome
$(1,2)$. The development and progression of SGTs, like other neoplasias result from multiple genetic alterations and molecular studies may help to understand the mechanisms involved in their tumorigenesis.

The development of cDNA microarray and proteomic techniques, allowed the analysis of thousands of genes 
or proteins in one single experiment, facilitating the identification of molecules with potential clinical applications $(3,4)$. In line with these new approaches, in 1998 Kononen et al. (5) promulgated the idea of translating the convenience of DNA microarrays to tissues. This new methodology allowed simultaneous screening of dozens of tumor specimens at once, being popularly called as tissue microarray (TMA) (6).

TMA technology has the potential to significantly accelerate in situ studies of tissue specimens, to explore associations between molecular changes and clinicpathological informations and to ensure preservation of unique and precious research materials. Briefly, tiny tissue cylinders are acquired from hundreds of different primary tumor blocks and arranged in a matrix configuration within a recipient paraffin block. Sections from such TMA blocks can then be used for simultaneous in situ analyses of up to 1000 tissue specimens either at the DNA, RNA or protein levels; providing maximal use of limited tissue resources $(3,6-8)$.

The use of this high-throughput technique significantly facilitates the identification of new molecular markers that could predict the clinical behavior of tumors, helping to better understand their pathogenesis and biological characteristics. However, very few studies have applied this technology in the evaluation of SGTs, and their known morphological heterogeneity could theoretically affect the validity of the results obtained. Therefore, the objective of this article is to present and discuss the design and building of TMA blocks of 238 SGTs, considering its relevant technical points.

\section{Material and Methods}

From January 2001 to December 2011, 493 cases of SGTs were retrieved from the archives of the Oral Pathology Department of the Piracicaba Dental School (161 cases) and from a Surgical Pathology laboratory of the Brazilian Southern state of Paraná (332 cases). Histological preparations stained with $H \& E$ were reviewed by three oral pathologists and, when necessary, new cuts were performed and stained with periodic acid-Schiff and mucicarmine. All cases were classified according to the 2005 World Health Organization's Histological Typing of Salivary Gland Tumors. Those primary SGTs that affected major or minor salivary glands were included in the study. Cases without enough tissue available for TMA construction, or those whose definitive salivary gland origin could not be confirmed, were excluded from the study. After this selection, 238 formalin-fixed, paraffin-embedded primary SGTs remained available for being arrayed.

Representative tumor areas were selected and marked on H\&E-stained sections using an objective marker (1.8 mm; Nikon Corporation, Tokyo, Japan). The slide was then overlaid on the original paraffin block to deter- mine the corresponding area to be used. TMA were constructed using a manual tissue arrayer (Sakura Co.; Japan). Three representative cylindrical cores of 1.0, 2.0 or $3.0 \mathrm{~mm}$ diameter were taken from each original tissue block and then arrayed sequentially into a recipient ready-to-use paraffin block (Sakura Co.; Japan). Two cores of normal parotid gland tissue and one of oral squamous cell carcinoma were inserted into the left upper corner of each recipient block as controls for future immunohistochemical reactions and for orientation when examining the slides. A map specifying the exact position of each case was made, to facilitate the interpretation of the histological and immunohistochemical results.

The current study has been approved by the Ethical Committee of the Piracicaba Dental School - State University of Campinas (Protocol 141/2011).

\section{Results}

Among the 238 SGTs used in the construction of the TMA blocks, there were 200 benign and 38 malignant tumors (Table 1). $72.7 \%$ of the cases involved major salivary glands (173 cases), whereas $27.3 \%$ affected intra-oral minor glands ( 65 cases). It was built 12 TMA blocks; from these, it was created 8 blocks of pleomorphic adenoma ( 6 of $2.0 \mathrm{~mm}$ cores, 1 of $1.0 \mathrm{~mm}$ cores and 1 of $3.0 \mathrm{~mm}$ cores), 1 block of Warthin tumor $(2.0 \mathrm{~mm}$ cores) and 1 block containing pleomorphic adenoma, Warthin tumor and canalicular adenoma ( $2.0 \mathrm{~mm}$ cores). The last 2 blocks were composed by $2.0 \mathrm{~mm}$ cores of malignant tumors that included mucoepidermoid carcinoma, adenoid cystic carcinoma, acinic cell carcinoma, polymorphous low-grade adenocarcinoma, epithelialmyoepithelial carcinoma, myoepithelial carcinoma, carcinoma ex-pleomorphic adenoma and adenocarcinoma not otherwise specified (Fig. 1).

Table 1. Histopathological distribution of the 238 salivary gland tumors used for construction of 12 TMA blocks.

\begin{tabular}{|l|c|c|}
\hline \multicolumn{1}{|c|}{ Tumors } & N & \% \\
\hline Benign & & \\
\hline Pleomorphic adenoma & 173 & 72.7 \\
\hline Warthin Tumor & 24 & 10.0 \\
\hline Canalicular adenoma & 3 & 1.3 \\
\hline Malignant & & \\
\hline Adenoid cystic carcnoma & 10 & 4.2 \\
\hline Mucoepidermoid Carcinoma & 10 & 4.2 \\
\hline Adenocarcinoma, Not Otherwise Specified & 4 & 1.7 \\
\hline Carcinoma Ex-Pleomorphic Adenoma & 4 & 1.7 \\
\hline Polimorphous Low-grade Adenocarcinoma & 4 & 1.7 \\
\hline Acinic Cell Carcinoma & 3 & 1.3 \\
\hline Epithelial-Myoepithelial Carcinoma & 2 & 0.8 \\
\hline Myoepithelial Carcinoma & 1 & 0.4 \\
\hline Total & 238 & 100.0 \\
\hline
\end{tabular}


A
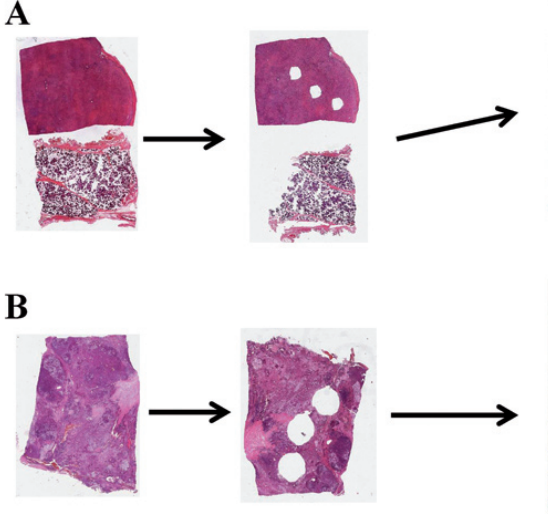

C

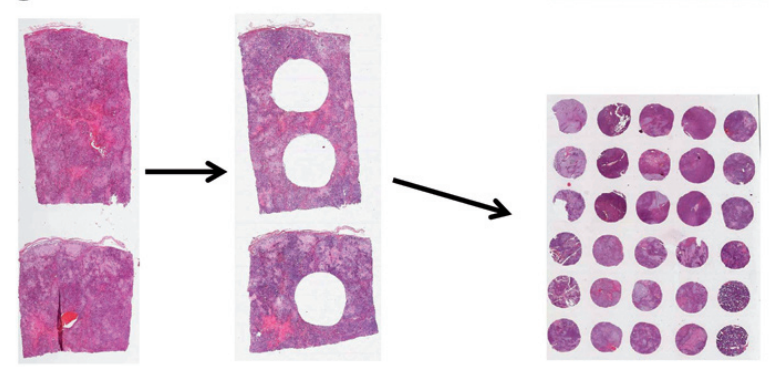

Fig. 1. Example of full tissue sections previously and after the acquisition of TMA cores of A) 1.0, B) 2.0 and C) $3.0 \mathrm{~mm}$. It can be seen that sections that provided larger cylinders became significantly more damaged than those that provided smaller cylinders. Microscopic images acquired using the Aperio ScanScope CS scanner.

Most of the time and efforts to construct the blocks were actually spent in the search, organization and pathological review of the tissue specimens to be included in the arrays, whereas the TMA building itself usually took from 1 to 2 hours for each block depending on the diameter of the cylinders used.

As expected, the use of larger needles caused more damage to the original tissue blocks. Hence, while those blocks that provided $1.0 \mathrm{~mm}$ cores could be used in other projects, most of those specimens that provided $3.0 \mathrm{~mm}$ cores could not be used again. In addition, larger needles substantially reduced the number of specimens that could be arrayed. TMA blocks composed by $2.0 \mathrm{~mm}$ cylinders allowed as many as 60 specimens to be arrayed into a ready-to-use recipient block of approximately $45 \times 20 \mathrm{~mm}$, what corresponded to 19 different cases plus controls. Those composed by $1.0 \mathrm{~mm}$ cylinders allowed 120 specimens, representing 39 cases; whereas those TMAs composed by $3.0 \mathrm{~mm}$ cylinders allowed only 30 specimens or 9 different cases, always using triplicate arrangement.

In approximately $5 \%$ of the cases there was a slight difference between the area selected in the H\&E-stained slide to be inserted in the TMA block and the one that in fact was inserted. It was considered that the rate of tissue loss attributable to tissue damage during TMA construction was about $3.7 \%$.

Most of the tumors were PA, and using three cores, highly representative areas of the tumor were obtained using either 1.0, 2.0 or $3.0 \mathrm{~mm}$ punches (Fig. 2). In tumors with a more homogenous morphological pattern, as canalicular adenoma and myoepithelial carcinoma, the representativity of the TMA was even higher. However, tumors rich in cystic spaces as low-grade mucoepidermoid carcinoma and Warthin tumor the tissue samples were not considered adequate, since only few neoplastic tissue was available in the TMA blocks (Fig. 3).

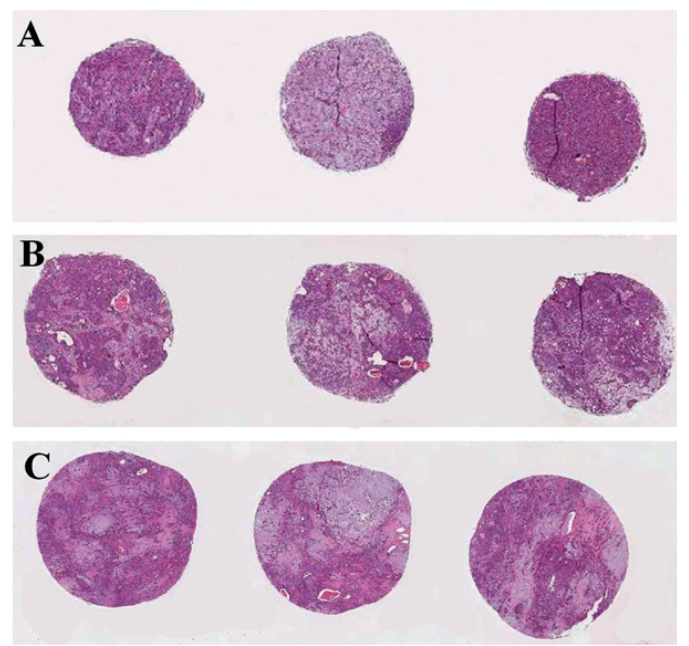

Fig. 2. Highly representative areas of pleomorphic adenoma in tissue cores of $1.0,2.0$ and $3.0 \mathrm{~mm}$.
A

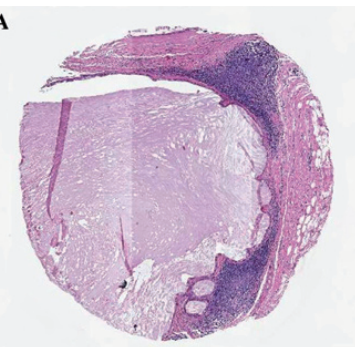

B

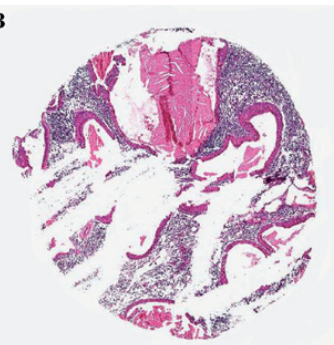

Fig. 3. In cases rich in cystic spaces as low-grade mucoepidermoid carcinoma and Warthin tumor, only few neoplastic tissue are found on the TMA cores.

\section{Discussion}

Tissue microarrays (TMAs) were developed by Kononen et al. (5) and are now widely accepted as a fast and cost-effective tool that facilitates the analysis of molecular alterations in thousands of tissue specimens by acquiring cylindrical cores of formalin-fixed, paraffinembedded tissue specimens and arraying them into a recipient block. These TMA blocks can be used for any 
in situ tissue analysis, including IHC, in situ hybridization, DNA ploidy, nuclear morphometry, and FISH (9). During the last decade, numerous studies have validated this method in the investigative surgical pathology. TMA cores as small as $0.6 \mathrm{~mm}$ have been confirmed to be adequate for analyzing breast cancer specimens by IHC for the expression of estrogen and progesterone receptors and the tyrosine kinase receptor HER-2 $(10,11)$. Similarly, TMA immunohistochemical staining for p53, cyclin D1, bcl-2, bax, Cox-2, $\beta$-catenin, c-myc, PTEN and p-Aktlenabled high-throughput analysis of genetic alterations that might contribute to human colon cancer development and progression (12). TMA validation has also been conducted in endometrial cancer (13), esophageal squamous cell carcinoma (14), lung cancer (15), cervical adenocarcinoma (16), ovarian carcinoma (17) and in many other human neoplasias.

The use of TMA for molecular studies of SGTs is scarce (Table 2) (1, 18-25). Iwafuchi et al. (18) first used TMA for analyzing molecular features of these tumors. By evaluating the expression of a large panel of proteins in different salivary gland neoplasias, these authors concluded that SGTs may be well characterized using markers only toward myoepithelial, luminal and basal cells. Also by IHC and TMA, Mcm-2 has been proved to be a proliferative sensitive marker for SGTs and PLUNC proteins have been suggested to be useful diagnostic tools for mucoepidermoid carcinoma, whereas geminin has been strongly associated with reduced overall and relapse-free survival rates in patients affected by salivary gland carcinomas $(1,19,20)$. Freier et al. (21) evaluated KIT expression in a large sample of histologically defined subgroups of adenoid cystic carcinoma, observing a stronger expression in cribriform and tubular subtypes when compared to the solid variant. Similarly, Freier et al. (22) analyzed the prevalence of chromosome 22q13 copy number gains in 70 ACC and found that it represents a decisive molecular event

Table 2. Studies previously published in the English literature using tissue microarray for molecular analysis of salivary gland tumors.

\begin{tabular}{|c|c|c|c|c|c|c|c|}
\hline \multirow{2}{*}{ Authors } & \multirow{2}{*}{ Country } & \multirow{2}{*}{ Sample } & \multirow{2}{*}{ Molecular markers } & \multicolumn{2}{|c|}{ TMA Cores } & \multirow{2}{*}{ Methods } & \multirow{2}{*}{ Results } \\
\hline & & & & Number & Size & & \\
\hline $\begin{array}{l}\text { Heiduschka et al, } \\
\text { 2011(24) }\end{array}$ & Austria & 108 & Mcl-1 & NS & NS & $\mathrm{IHC}$ & $\begin{array}{l}\text { Parotid gland malignancies produce } \\
\text { high levels of Mcl-1 protein. }\end{array}$ \\
\hline $\begin{array}{l}\text { Clauditz et al, } \\
2011(23)\end{array}$ & Germany & 1109 & HER-2 & NS & NS & FISH, IHC & $\begin{array}{l}\text { HER-2 overexpression was observed in } \\
\text { about } 20 \% \text { of patients with salivary } \\
\text { duct cancers. }\end{array}$ \\
\hline $\begin{array}{l}\text { Williams et al, } \\
2010(25)\end{array}$ & USA & 66 & HER-2, EGFR, Chromosomes 7 and 17 & NS & $1.0 \mathrm{~mm}$ & FISH, IHC & $\begin{array}{l}\text { HER-2 gene amplification and protein } \\
\text { high expression, may be selected for } \\
\text { targeted therapy. }\end{array}$ \\
\hline $\begin{array}{l}\text { Yamazaki et al, } \\
2010(1)\end{array}$ & Japan & 170 & Geminin and Ki-67 & 02 & $2.0 \mathrm{~mm}$ & $\mathrm{IHC}$ & $\begin{array}{l}\text { Geminin expression is a useful marker } \\
\text { for predicting salivary gland carcinoma } \\
\text { aggressiveness. }\end{array}$ \\
\hline $\begin{array}{l}\text { Vargas et al, } \\
2008(20)\end{array}$ & UK & 64 & SPLUNC1, SPLUNC2 and LPLUNC1 & 03 & $1.0 \mathrm{~mm}$ & $\mathrm{IHC}$ & $\begin{array}{l}\text { Presence of an intense expression of } \\
\text { two PLUNC proteins in mucous cells } \\
\text { and mucin plugs of mucoepidermoid } \\
\text { carcinoma and papillary } \\
\text { cystadenocarcinoma. }\end{array}$ \\
\hline $\begin{array}{l}\text { Vargas et al, } \\
2008(19)\end{array}$ & UK & 62 & Mcm-2, Ki-67 and Geminin & 03 & $1.0 \mathrm{~mm}$ & $\mathrm{IHC}$ & $\begin{array}{l}\text { Mcm-2 may be a sensitive proliferation } \\
\text { marker in SGTs and may be useful for } \\
\text { differential diagnosis. }\end{array}$ \\
\hline $\begin{array}{l}\text { Freier et al, } \\
2005(21)\end{array}$ & Germany & 70 & Chromosome 22q13 & 02 & $0.6 \mathrm{~mm}$ & FISH & $\begin{array}{l}\text { Copy number gain of } 22 \mathrm{q} 13 \text { as a } \\
\text { frequent finding in } \mathrm{ACC} \text { irrespective of } \\
\text { histological variant. }\end{array}$ \\
\hline $\begin{array}{l}\text { Freier et al, } \\
2005(22)\end{array}$ & Germany & $\begin{array}{l}55 \text { for IHC } \\
49 \text { for FISH }\end{array}$ & KIT & NS & $0.6 \mathrm{~mm}$ & FISH, IHC & $\begin{array}{l}\text { Stronger expression in cribriform and } \\
\text { tubular subtypes if compared to solid } \\
\text { variant. }\end{array}$ \\
\hline $\begin{array}{l}\text { Iwafuchi et al, } \\
\text { 2004(19) }\end{array}$ & Japan & 88 & $\begin{array}{l}\text { Caldesmon, aSMA, CD10, calponin, } \\
\text { CD44v6, Ck7, Ck19, Ck8, p63, Ck14, } \\
\text { 14-3-30 and Maspin }\end{array}$ & 04 & $0.6 \mathrm{~mm}$ & $\mathrm{IHC}$ & $\begin{array}{l}\text { Salivary gland tumors may be well } \\
\text { characterized by using makers toward } \\
\text { only three components, myoepithelial, } \\
\text { luminal and basal cells. }\end{array}$ \\
\hline
\end{tabular}

NS: Not specified; IHC: Immunohistochemistry; FISH: Fluorescence in situ hybridization; UK: United Kingdom; USA: United States of America. 
in early stages of ACC, irrespective of histologic differentiation. However, despite these interesting results previously described, there are no reports describing and evaluating the most important technical points to the construction of TMA blocks for studying SGTs.

TMAs present various relevant advantages for molecular studies of paraffin embedded tissues. It permits the concomitant use of a large number of cases and significantly reduces the experimental handling time (3). Moreover, as the reactions are done in one single slide, the reagent concentrations, incubation times, temperature, wash conditions, and antigen retrieval are the same for all specimens. The necessary reagent volume is significantly reduced, making it a very cost-effective method $(6,26)$. In our study, using ready-to-use recipient TMA blocks, it was possible to resume our whole 238 neoplastic samples to only 12 blocks, facilitating the evaluation of molecular markers in this large number of cases. In addition, the use of TMAs preserves precious and finite tissue resources and maximizes the number of experiments that can be performed with the material present in one paraffin block (6).

Whereas large tissue sections are used for histological diagnosis, TMA has been reserved for research purposes. However, tumor heterogeneity has traditionally been recognized as a potential problem for those using TMAs, and the most used $0.6 \mathrm{~mm}$ cores have been perceived as too small and potentially not representative of the entire specimen. Taking multiple samples of each tumor seems to be the most direct way of combating the potential lack of representativeness in a certain tissue (7). Recent reports achieved 95\% accuracy with only two cores, whereas most studies indicate that triplicate TMA cores have up to $98 \%$ concordance when compared with the results of full sections $(3,16)$. Other alternative would be the use of larger punch needles; however, the increase in the number of cores and their diameters leads to a considerable damaged donor block and fewer samples arrayed (7). Evaluating the histological features present in the cores obtained in the present study, it could be noted that triplicate cores of 1.0, 2.0 and $3.0 \mathrm{~mm}$ were all well representative of the original tissue, although $3.0 \mathrm{~mm}$ cores evidently offered more neoplastic cells and structures to be evaluated than 1.0 and $2.0 \mathrm{~mm}$ cores. However, only 9 cases could be inserted in a TMA recipient block when $3 \mathrm{~mm}$ cylinders were used, whereas up to 39 could be arrayed when $1 \mathrm{~mm}$ were taken; moreover, smaller diameters better preserved the donor blocks for future studies.

Improper selection of representative tumor areas on the H\&E original slide by the pathologist, or incorrect punching of these representative areas can cause tissue cores that contain inadequate areas to be studied (6). In the current study, it was noted that in a small percentage of cases, the neoplastic area inserted in the recipient block was not the exact area selected in the H\&E slide, what may also be attributable to differences in the tissue contraction in the original paraffin donor block.

Finally, due to the small size of the cylinders and the high number of samples, TMA cores are much more prone to be lost during sectioning than full sections. The total number of lost cores due to technical reasons has been estimated to vary from 4 to $23 \%(14,16,27)$. In the building process of the TMA blocks in the present study, $3.7 \%$ of the cores were lost; however, this rate would probably increase if the samples were submitted to IHC procedures.

In conclusion, tissue microarray is a high-throughput, cost-effective and tissue-saving technique in molecular analysis of formalin-fixed, paraffin-embedded neoplasias, helping to overcome the ordinary time-consuming work. The present study showed the usefulness of this technique in the construction of SGTs TMA blocks, revealing that solid tumors are more indicated to be micro-arrayed than their cystic counterparts. These TMA blocks will now be used for immunohistochemical studies to better evaluate SGT's molecular features.

\section{References}

1. Yamazaki M, Fujii S, Murata Y, Hayashi R, Ochiai A. High expression level of geminin predicts a poor clinical outcome in salivary gland carcinomas. Histopathology. 2010;56:883-92.

2.Vargas PA, Gerhard R, Araújo Filho VJ, de Castro IV. Salivary gland tumors in a Brazilian Population: A retrospective study of 124 cases. Rev Hosp Clin Fac Med Sao Paulo. 2002;57:271-6.

3.Torhorst J, Bucher C, Kononen J, Haas P, Zuber M, Köchli OR, et al. Tissue microarray for rapid linking of molecular changes to clinical endpoints. Am J Pathol. 2001;159:2249-56.

4. Simon R, Sauter G. Tissue microarrays for miniaturized high-throughput molecular profiling of tumors. Exp Hematol. 2002;30:1365-72.

5. Kononen J, Bubendorf L, Kallioniemi A, Bärlund M, Schraml P, Leighton $\mathrm{S}$, et al. Tissue microarrays for high-throughput molecular profiling of tumor specimens. Nat Med. 1998;4:844-7.

6. Radhakrishnan R, Solomon M, Satyamoorthy K, Martin LE, Lingen MW. Tissue microarray - a high-throughput molecular analysis in head and neck cancer. J Oral Pathol Med. 2008;37:166-76.

7. Nocito A, Kononen J, Kallioniemi OP, Sauter G. Tissue microarrays (TMAs) for high-throughput molecular pathology research. Int J Cancer. 2001;94:1-5.

8. Voduc D, Kenney C, Nielsen TO. Tissue microarrays in clinical oncology. Semin Radiat Oncol. 2008;18:89-97.

9. Kallioniemi OP, Wagner U, Kononen J, Sauter G. Tissue microarray technology for high-throughput molecular profiling of cancer. Hum Mol Genet. 2001;10:657-62.

10. Henriksen KL, Rasmussen BB, Lykkesfeldt AE, Møller S, Ejlertsen B, Mouridsen HT. Semi-quantitative scoring of potentially predictive markers for endocrine treatment of breast cancer: a comparison between whole sections and tissue microarrays. J Clin Pathol. 2007;60:397-404.

11. Alkushi A. Validation of tissue microarray biomarker expression of breast carcinomas in Saudi women. Hematol Oncol Stem Cell Ther. 2009;2:394-8.

12. Chen WC, Lin MS, Zhang BF, Fang J, Zhou Q, Hu Y, et al. Survey of molecular profiling during human colon cancer development and progression by immunohistochemical staining on tissue microarray. World J Gastroenterol. 2007;13:699-708.

13. Fons G, Hasibuan SM, van der Velden J, ten Kate FJ. Validation 
of tissue microarray technology in endometrioid cancer of the endometrium. J Clin Pathol. 2007;60:500-3.

14. Boone J, van Hillegersberg R, van Diest PJ, Offerhaus GJ, Rinkes IH, Kate FJ. Validation of tissue microarray technology in squamous cell carcinoma of the esophagus. Virchows Arch. 2008;452:507-14. 15. Leversha MA, Fielding P, Watson S, Gosney JR, Field JK. Expression of p53, pRB, and p16 in lung tumours: a validation study on tissue microarrays. J Pathol. 2003;200:610-9.

16. Tawfik El-Mansi M, Williams AR. Validation of tissue microarray technology using cervical adenocarcinoma and its precursors as a model system. Int J Gynecol Cancer. 2006;16:1225-33.

17. Rosen DG, Huang X, Deavers MT, Malpica A, Silva EG, Liu J. Validation of tissue microarray technology in ovarian carcinoma. Mod Pathol. 2004;17:790-7.

18. Iwafuchi H, Mori N, Takahashi T, Yatabe Y. Phenotypic composition of salivary gland tumors: an application of principle component analysis to tissue microarray data. Mod Pathol. 2004;17:803-10.

19. Vargas PA, Cheng Y, Barrett AW, Craig GT, Speight PM. Expression of Mcm-2, Ki-67 and geminin in benign and malignant salivary gland tumours. J Oral Pathol Med. 2008;37:309-18.

20. Vargas PA, Speight PM, Bingle CD, Barrett AW, Bingle L. Expression of PLUNC family members in benign and malignant salivary gland tumours. Oral Dis. 2008;14:613-9.

21. Freier K, Flechtenmacher C, Walch A, Devens F, Mühling J, Lichter P, et al. Differential KIT expression in histological subtypes of adenoid cystic carcinoma (ACC) of the salivary gland. Oral Oncol. 2005;41:934-9.

22. Freier K, Flechtenmacher C, Walch A, Ohl S, Devens F, Burke B, et al. Copy number gains on 22q13 in adenoid cystic carcinoma of the salivary gland revealed by comparative genomic hybridization and tissue microarray analysis. Cancer Genet Cytogenet. 2005;159:8995.

23. Clauditz TS, Reiff M, Gravert L, Gnoss A, Tsourlakis MC, Münscher A, et al. Human epidermal growth factor receptor 2 (HER2) in salivary gland carcinomas. Pathology. 2011;43:459-64.

24. Heiduschka G, Erovic BM, Pammer J, Kotowski U, Kaider A, Ch Grasl M, et al. Mcl-1 expression is up-regulated in malignancies of the parotid gland. Dis Markers. 2011;30:229-33.

25. Williams MD, Roberts DB, Kies MS, Mao L, Weber RS, El-Naggar AK. Genetic and expression analysis of HER-2 and EGFR genes in salivary duct carcinoma: Empirical and therapeutic significance. Clin Cancer Res. 2010;16:2266-74.

26. Goldstine J, Seligson DB, Beizai P, Miyata H, Vinters HV. Tissue microarrays in the study of non-neoplastic disease of the nervous system. J Neuropathol Exp Neurol. 2002;61:653-62.

27. Hager M, Kolbitsch C, Tiefenthaler W, Haufe H, Kemmerling R, Lucia Moser P. Tissue microarrays from renal cell tumors: exclusion criteria and rate of exclusion. Scand J Urol Nephrol. 2007;41:485-9.

\section{Acknowledgement}

The authors state that they have no potential conflict of interest that could bias the results obtained in the current study and that this study has been supported by grants of the Brazilian Coordination of Higher Education (CAPES-Brasil) and from the São Paulo Research Foundation (FAPESP 2009/53839-2). 